\title{
Invited Commentary: National Safe Place: Meeting the Immediate Needs of Runaway and Homeless Youth
}

\author{
Sara M. Walsh • Robin E. Donaldson
}

Published online: 16 March 2010

(C) Springer Science+Business Media, LLC 2010

\begin{abstract}
An estimated 1.6 million youth run away from home each year. While on the run, these youth are vulnerable to exploitation, victimization, increased dangers and perpetration of criminal behavior. Runaway and homeless youth are far more likely to engage in substance use and delinquent behavior, drop out of school and suffer from sexually transmitted diseases and mental illness at greater rates than the norm. Timely and direct intervention in runaway and throwaway cases is imperative to protect youth from the high risks of living on the streets. National Safe Place is an outreach and prevention program that is uniquely designed to provide immediate safety and access to services for any youth in need. In partnership with over 360 youth serving agencies and over 10,000 businesses and community organizations across the United States, the Safe Place program educates youth about alternatives to running away and homelessness and provides easily accessible links to service providers. Ongoing data collection indicates that National Safe Place has been successful in reaching endangered youth at risk of abuse, neglect or serious family problems but that expanded program models remain needed. The challenges and successes of current programming and the future of National Safe Place program expansion are discussed.
\end{abstract}

Keywords Runaway - Throwaway · Homeless ·

Safe place $\cdot$ Outreach

\section{S. M. Walsh $(\bowtie)$}

Department of Criminal Justice, Indiana University,

Bloomington, IN, USA

e-mail: smwalsh@indiana.edu

R. E. Donaldson

National Safe Place, Louisville, USA

e-mail: rdonaldson@nationalsafeplace.org
It is estimated that 1.6 million young people run away from home each year (Sedlak et al. 2002). The National Safe Place (NSP) program is a prevention and outreach program which connects youth experiencing a crisis situation to immediate help and support. For the nearly 1,700 runway or homeless youth who sought help through Safe Place in 2009 alone, access to services provided them with a safe place to sleep, food and necessary medical care, education and other help away from the dangers of the streets. NSP is not only an intervention program for those youth already on the streets but a prevention program for those youth at risk of displacement. By providing immediate safety and an easily accessible link to services for both the youth and their families, Safe Place reduces the number of youth on the streets. The NSP program reaches out to youth to make sure they can access help easily where they are, at any time of day or night. Youth only need to know to look for the ubiquitous Safe Place sign and ask for help at a designated location where the staff are trained to immediately respond to connect the youth to services or text message the word SAFE and their current location to the new Txt 4 Help number.

The Safe Place program is a community collaboration program unique in its partnership of businesses, youth service agencies, community leaders and dedicated volunteers. The local youth serving agencies are able to provide direct services or service referral for the youth and families. This collaboration and direct service eliminates the need for residential placement or provides youth and families temporary respite while services are put into place.

Perhaps even more unique is NSP's focus on youth as those who initiate the service. By definition, a Safe Place incident request for help must be made voluntarily by the youth receiving services. For many youth, requesting help through Safe Place is their first step to access to services for 
themselves and their families. Safe Place is designed as an early prevention program so that youth, regardless of their needs, can be connected to services and help before problems escalate beyond control. The link to early intervention can be key to reducing the risk of running away and homelessness among youth and Safe Place is often the entry point to services for many youth and families.

\section{Runaway, Throwaway and Homeless Youth at Risk}

Researchers have long known that runaway and homeless youth suffer from high rates of behavioral and mental health problems. According to a report by the US General Accounting Office (1989), staff at youth shelters report that of the runaways that they work with: $63 \%$ report depression, $50 \%$ have problems at school, $20 \%$ have drug and alcohol abuse problems, $17 \%$ have been in trouble with the juvenile justice system, and $12 \%$ are possibly suicidal. These youth also often come from troubled backgrounds and tumultuous family situations.

Physical and sexual abuse, domestic violence and disharmony among parents are primary reasons that youth leave home (Dedel 2006). According to the National Runaway Switchboard (2008) "Family dynamics" is the most frequently cited problem $(29 \%)$ by callers and "family problems" has consistently been the number one reason that youth seek help through Safe Place. Previous research reports that nearly half of the youth in shelters had specifically been told to leave home (Ringwalt et al. 1998). Although male and female youth are equally likely to run away from home (Hammer et al. 2002), the abuse rates for females are higher. In a study of youth on the street, Molnar et al. (1998) reported that, among runaway youth, $35 \%$ of males and females reported physical abuse but $70 \%$ of females and $24 \%$ of males reported sexual abuse before leaving home. Research on homeless youth finds that, in general, the rates of reported physical abuse range from 16-81 to $5-50 \%$ for sexual abuse (Baron 2003). This childhood physical and sexual abuse in turn increases youths' risk for victimization on the street (Baron 2003) and suicide (Molnar et al. 1998). Runaway youth are thus not only likely to be running from a physically or sexually abusive situation but also highly vulnerable to sexual assaults and physical dangers once on the street.

Because they are reluctant to report crimes that they witness or that are committed against them, homeless youth are frequently exposed to violence (Kipke et al. 1997). Youth without access to social service resources, including shelters, also have an increased tendency to become homeless and to engage in criminal activities (Hagan and McCarthy 1998). Homeless youth often turn to illegal and high-risk activities to survive (Benoit-Bryan 2008), such as trading sex (Greene et al. 1999) and dealing drugs (Whitbeck et al. 2001). These high risk behaviors increase youth's exposure to offenders (Baron 2003) and exploitive/ deviant peers (Whitbeck et al. 1999). As a result of these high risk factors, homeless youth are also at great risk for pregnancy and disease. The pregnancy rate among homeless youth is estimated at over four times the rate of athome youth (Thompson et al. 2008) and 6-31\% report a past pregnancy (Greene and Ringwalt 1998). Runway youth have also been estimated to be 6-12 times more likely to become infected with the HIV virus than their at-home peers (Rotherman-Borus et al. 2003). This tremendously increased mortality and morbidity risk is associated with homeless and runaway youths' frequent exposure to violence on the streets and the deviant or criminal survival strategies by youth who are often already running form extensive histories of violence at home.

\section{Challenges to Intervention and Prevention of Youth Homelessness}

Crisis intervention and social services to youth and their families at the local level are often hindered. Awareness of the runaway and homeless youth problem is lacking at community levels and families in crisis are often reluctant to seek help from those local agencies that are responsive. Further complicating local intervention are funding issues that arise during economic difficulties which cause individuals as well as local, state and federal leaders to largely disengage from the problem.

While there appears to be federal awareness and recognition of runaway and homeless youth, recognition and awareness often fails to occur at the local level. Contributing to the lack of awareness at the local level is the difficulty of accurately measuring the incidence of runaway and homeless youth and the varying federal definitions of homeless youth. For example, many Safe Place coordinators are told by school and community officials that runaway and homeless youth are not a problem within the community (S. Elder, personal communication 2009). The lack of concern that the general population demonstrates in regard to runaway and homeless youth and the perception of this population as troublemakers is a concern that is echoed throughout communities across the nation (R. Donaldson, personal communication 2009). Many individuals see this as a problem for the youths family to address and do not view it as an issue that impacts them personally.

In 2009, six Colorado counties participated in a federally funded Community Readiness Assessment (CRA) designed to measure the ability of a community to support and effectively implement programming designed to serve 
runaway and homeless youth (Center for Systems Integration 2009). Almost across the board, the assessments revealed that comprehensive education and outreach was needed to secure a greater understanding of the issue of runaway and homeless youth among the community residents. Six different dimensions were assessed by the CRA: community's efforts related to the issue, knowledge of these efforts, knowledge about the specific issue, existing resources, community climate and leadership support and capacity. Each dimension was scored on a scale of one (Building Awareness) to nine (Community Investment and Commitment). Of the six communities, only one community scored above a two on the dimensions of "knowledge of the issue" and "community climate". Local Safe Place coordinators across the country provide anecdotal evidence that this lack of recognition often translates into difficulty providing immediate prevention, intervention, outreach and education to youth (S. Elder, personal communication 2009).

Another barrier at the local level is the tension that exists between child welfare agencies and service recipients. According to a 2002 study:

Child welfare staff were often perceived as culturally insensitive, unaccepting of alternative methods of child rearing and unresponsive to the underlying problems that may have led to child maltreatment. These issues were further exacerbated by the fact that child welfare agency staff tended to be better educated and less ethnically diverse than the communities in which the majority of investigations and child removals occurred (James Bell Associates 2002).

In addition, the National Study of Protective, Preventive and Reunification Services Delivered to Children and Their Families found that "African-American and Hispanic children are more likely to be placed in foster care than white children even when case problems and characteristics should have kept them out of care" (US Department of Health and Human Services 1994, p. 7.4). The perceived cultural and racial insensitivity of child welfare staff thus creates a reluctance of families in crisis to engage with the key community agency designed to serve them.

Community and nonprofit social services agencies other than child welfare agencies exist; however, in the recent trying economic times, social service agencies have been forced to cut their budgets, resulting in a loss of programs and staff. State budgets take a significant hit with economic downturns and often the first and most significant loss is in social services. Basic Centers, Street Outreach, Transitional Living Programs and other programs designed to provide services to runaway and homeless youth are funded by federal appropriations for the Reconnecting Homeless Youth (RHY) Act for which funds have been held at a nearly constant level for the last decade. Because of an increased need for services and competition for funding, many long-standing emergency youth shelters and youthserving organizations have lost funding for programs. In some cases, the loss of federal dollars has resulted in agencies being forced to end services. A more widespread result has been the loss of staff and a diminished capacity for serving youth in need. While the 2009 federal appropriation included a minimal increase for RHY funded programs, it has not filled the gap that has been left by the loss of programs in previous years. Youth-serving agencies are often overwhelmed in trying to maintain and provide services and do not have the significant time or staff to organize advocacy effort for continued funding.

\section{Safe Place Design and Implementation}

National Safe Place fulfills its mission to provide youth with immediate safety and access to services through partnerships with community locations that create additional access points to youth-serving agencies. Safe Place works by designating fast food restaurants, convenience stores and community buildings (i.e., fire stations and libraries) as Safe Place locations. In many communities, the city or area transit authority buses are also mobile Safe Place locations. Each location displays the distinctive, diamond-shaped yellow and black Safe Place logo on the exterior of their building. Any young person experiencing a crisis situation can walk into a Safe Place location and ask for help. A call is made from the site and within minutes a trained volunteer will meet with the youth to help assess what is needed. If youth need counseling or shelter they are transported to the nearby youth shelter. There are 138 Safe Place programs across the country in 38 states and the District of Columbia. With over 17,000 participating sites nationally, youth can look for the distinctive yellow and black Safe Place sign which marks locations ready serve as access points to immediate help for any youth at risk. Volunteers are available in each Safe Place community to respond to youth at designated Safe Place sites. Approximately 150,000 employees stand ready to offer assistance to any young person seeking help at their location. Once a site agrees to display the Safe Place sign on its building, there is an inherent promise to youth that safety and help is guaranteed at that location.

In addition to the noticeable Safe Place signs throughout communities, NSP has furthered its visibility by launching a "Txt 4 Help" initiative in October of 2009. The texting initiative adds an additional 200 plus emergency youth shelters across the country available to respond to youth in need. Youth in crisis now can text the word SAFE and their current location to the number 69866 and they will receive 
an address for the closest Safe Place site and contact number for the local youth shelter. In cities that do not yet have a Safe Place program, the youth will receive the name and number of the nearest youth shelter. If there is not a local Safe Place program or youth shelter, the youth will receive the number for the national hotline. With the launch of the Txt 4 Help national texting initiative, youth with access to mobile phones are within seconds of a response which will connect them to a site, the local youth shelter or the National Runaway Switchboard hotline. Almost $90 \%$ of teens have regular access to a mobile phone; $83 \%$ of teens with mobile phone access use textmessaging and $66 \%$ prefer text-messaging over calling (Nielsen Company 2009). The new Txt 4 Help program has the ability to reach even more youth in crisis than NSP has reached by traditional means.

\section{Safe Place Efficacy}

National Safe Place is effective in outreach to a diverse array of youth in crisis. From 1987 through 2009, Safe Place has provided services at no cost to more than 119,000 youth who sought help at Safe Place locations nationwide. An additional 126,051 youth have been counseled by phone and more than six million youth have received information about the Safe Place program and youthserving agencies that provide help and resources to youth in need. There are over 17,000 Safe Place sites across the country in 38 states.

Immediate recognition of the Safe Place logo, and its promise of safety, is essential when youth are in crisis. Awareness of the NSP logo is built through promotional activities and educational presentations. These presentations also educate youth on alternatives to running away. Each year an average of two million young people learn through presentations, often at schools, that seeking help when experiencing a crisis is a better decision than running from home. At these presentations, youth are provided with information about the services of the local youth serving agency and how to access help via designated Safe Place locations or the Txt 4 Help program.

The goal of most services provided by local Safe Place host agencies is to build skills, support systems, and resources for youth and families that they assist. By building skills and support, young people and families are able to successfully function autonomously and independently of service providers. In reported cases for 2009, nearly $80 \%$ of the youth helped through Safe Place exited the program with the identified problem no longer present or a service plan in place to address the problem. The remainder either declined services $(10 \%)$, left the program before a plan was developed $(5 \%)$ or had no plan reported for them $(5 \%)$. These recent findings highlight NSP's effectiveness and positive impact on the youth they serve.

The Safe Place prevention and outreach program is designed to simultaneously increase protective factors and decrease risk factors that impact youth development. The types of services that agencies provide to youth help families identify and resolve factors that contribute to family stress, perpetuate negative behavior patterns and prohibit families from breaking the cycle of poverty. For example, access to immediate safety and shelter allows the youth to stay in school. Of homeless youth 16 years of age or older, $50 \%$ reported having been expelled, suspended or dropped out of school (US General Accounting Office 1989). Disruption in school attendance is often cited as a contributing factor to dropping out of school. Lack of education, in turn, is a factor that contributes to poverty. By helping to provide immediate support and shelter for runaway and homeless youth, Safe Place seeks to reduce disruption in youths' education.

While Safe Place interventions provide youth with immediate safety, it is the access to services and resources that provides youth with the needed support, opportunities for growth, and nurturing relationships. Supportive and nurturing relationships have been identified as one of the most important components of resiliency and personal growth (Condly 2006). NSPs partnerships with local youthserving organizations link youth with supportive services needed to help build positive support systems for themselves and their families.

\section{Program Expansion}

NSP programs provide standardized service delivery to youth in need and have proven to be effective with heterogeneous youth populations from multiple environments, including rural, urban and suburban areas. The 2009 Safe Place Coordinator survey revealed that as a result of NSP affiliation nearly $100 \%$ of responding of agencies had: created new partnerships with local businesses and community services, increased their effectiveness in reaching youth, seen an increase in community leader action to reduce youth homelessness and obtained new funding opportunities. Currently however, Safe Place has only two implementation models: the emergency shelter model and the community collaboration/host home model. Both of these existing models require a residential component to the program for youth seeking help who cannot safely return home. The emergency youth shelter model is the most commonly implemented, and it is the dominant model in urban areas. In rural communities, the community collaboration/host home model (similar to foster homes) will 
be adopted and provide the residential component for Safe Place by making it available in communities with otherwise limited resources and fewer youth. The requirement of either an emergency youth shelter or host home program prevents communities that have neither from implementing the Safe Place program, and this needed component can be problematic for communities that would like to implement Sage Place programs. The extent to which this is a concern is revealed by NSP's receiving a yearly average of more than 100 inquiries from communities interested in establishing a Safe Place program and that typically result in frustration for the community leaders who wish to make this program available. NSP recognizes that national expansion of the program will require different models of program implementation and is considering rural demonstration models, transit models and nonresidential models. Additional implementation models will increase youths' access to safe, supportive resources at the earliest possible stage of a crisis.

The rural demonstration model arose out of the need for an outreach plan for those communities across the country receiving federal funding for Rural Demonstration programs designed to expand services to runaway and homeless youth in rural areas without shelter facilities. Organizations funded through the Rural Host Homes Demonstration Project recruit, screen, train, and provide ongoing support to families that provide services to youth in their homes. The value of Safe Place as an effective outreach model was recognized by both the grant recipients and the federal administrators to those programs. NSP has been contacted by five of the six grantees from Iowa, Illinois, Minnesota, Colorado and Mississippi and is working with these communities to design a rural demonstration Safe Place implementation plan. The transit only model will be developed and piloted by the Cleveland Transit Authority and local youth-serving organizations in the Cleveland area. The Cleveland buses will serve as mobile Safe Place sites and youth will be able to access services by requesting help and being transported to the identified youth-serving organization. Currently transit systems in more than 60 communities across the country participate as mobile Safe Place sites; thus policies and procedures for transit use are already in place and can be adapted for the transit only model. Additionally, the NSP Advisory Board is exploring Safe Place implementation in communities that lack emergency residential services for youth in need. Possibilities being explored for program implementation in these communities include working with the local United Way agency, domestic violence shelters and/or Department of Child/Family Services. NSP will only consider such a model if confident that the services provided through the participating agencies will effectively meet the needs of the youth seeking help.

\section{Comprehensive Agency Model}

Effectively meeting the needs of individual youth in crisis requires a high level of effectiveness at the local partner agency level. Through anecdotal information, there appeared to be a difference between successful and struggling partnering agencies in Safe Place program implementation. In 2009, case studies were conducted to explore these differences and to determine the factors that distinguished successful programs from struggling programs. The results demonstrated that agencies that share the many and varied responsibilities related to implementing a Safe Place program among staff have stronger, more functional programs. While one staff member continued to coordinate efforts, the tasks of youth outreach, business recruitment, public awareness, site maintenance and reporting of data were distributed among agency personnel already engaged in similar activities. This distribution of tasks and responsibilities resulted in more successful programs and, as a result, NSP is developing a comprehensive Safe Place approach to assist agencies that are implementing the Safe Place program.

The Comprehensive Agency Model approach will strengthen the capacity of Safe Place agencies to deliver services to runaway, homeless and at-risk youth, build effective community partnerships and increase and diversify human and financial resources. This will be accomplished by integrating Safe Place responsibilities into key positions to maximize program effectiveness and minimize potential overload on any one staff. The NSP office facilitates this shift to the comprehensive agency approach through several different methods including a revision of the annual agency progress goals. For 2010, these goals incorporated activities that engage multiple agency staff members at varying levels to ensure successful programming. The Safe Place Operations Manual has been revised to reflect the shift to a Comprehensive Agency Model approach with suggestions on how agency personnel can assist the successful implementation of the program. In support of this shift to a Comprehensive Agency Model, NSP announced a "Grand Re-Opening" of the program During National Safe Place week in March 2010 and shared the results of the case study report, the latest new initiatives and training and support available to facilitate agencies in their shift to the comprehensive approach.

\section{Funding Challenges}

NSP continues to expand guidance and assistance to youth shelters in order to build the capacity of agency services. However, NSP receives no federally appropriated funds to operate. The program is supported through diversified 
funding which includes grants, corporate support, donations and social enterprise. Difficult funding environments weaken the ability of agencies to create new Safe Place programs or sustain existing efforts; agencies are not certain where funds are going to come from in order to maintain the work they currently do, much less start a new initiative. NSP experienced significant funding cuts in 2009, which resulted in the loss of highly valued staff positions. Staffing has been supplemented at varying intervals by local university interns, part-time staff, paid volunteers through AmeriCorps VISTA and AARP and unpaid volunteers. While some job responsibilities are absorbed by the remaining staff, the loss of personnel decreases the amount of services that can be offered to local partners, particularly in the area of development.

Although NSP receives no appropriated funds to support the 138 youth shelters and host home programs implementing the Safe Place program, the Safe Place program was recognized as an effective outreach program at the White House Conference for Missing, Exploited and Runaway Youth in 2002 by the Associate Commissioner of the Administration for Children, Youth and Families. The program is recognized by regional monitors of the Administration of Children and Families division of Family and Youth Service Bureau as an outreach and prevention program that can be utilized by their Basic Center and Street Outreach federal grantees. Likewise, some federal administrators across the country recognize the value of Safe Place to youth shelters and outreach programs and support its use. With support for NSP as a federal grantee through the Family and Youth Services Bureau, which administers the Basic Center and Street Outreach grants, more deliberate partnering with grantees could occur. Additionally, appropriated federal support would allow NSP to provide financial support to partnering agencies through sub-grants to reinforce local Safe Place efforts. Support through federal funding would thus enhance the effectiveness of NSP and its partner agencies to provide help and safety to youth at serious risk for violence, abuse, neglect or serious family and social problems.

\section{Program Evaluation}

With funders, both private and governmental, increasingly demanding successful outcome measures for programming and services through evaluation and research, the services for runaway and homeless youth are less competitive and less successful in securing dollars. Outcomes are difficult to measure in youth services for many reasons including confidentiality and consent issues as well as high client mobility which makes follow-up difficult. Thus, historically, social service programs have focused on outputs (number of clients, number of service hours provided, etc.) rather than outcomes (the actual impact of service participation). Recognizing the need to establish and implement strong evaluation and outcome measurements, the 20092011 National Safe Place Strategic Plan incorporated a conscious shift to evidence-based evaluation and programming. Since the summer of 2008, a NSP database has been designed and expanded to collect data that will allow for evaluation of Safe Place program impact. Additional measures have been designed to evaluate the quality of program implementation in the areas of outreach, training and site maintenance. Specific evaluation tools have been introduced to collect outcome data including pre/post student presentation worksheets, youth evaluations and client information sheets. Client information data include service plans upon exiting the program.

Data for the pre/post worksheets have been gathered since October 1, 2008. Since that time nearly 1400 pre/post worksheets have been uploaded into the NSP online database. A brief analysis of the data indicates that, since October 1, 2008, the large majority of youth (84\%) report on the pre-test that they know how to get help if they need it. That figure rises to $93 \%$ after the youth have participated in a Safe Place presentation. In the pre-test data, $48 \%$ of youth indicated a likelihood of using the Safe Place program if they found themselves in a situation of immediate danger or had a personal problem for which they needed help. That number rose to nearly $76 \%$ after learning about the program. This early data demonstrates the effectiveness of outreach efforts in terms of knowledge gained by youth as a result of outreach efforts and likelihood of program use.

The youth evaluation component allows for the collection of information that serves two purposes: quality assurance of the program and impact on the youth as reported by the youth themselves. Early analysis of evaluations are encouraging - with the vast majority of youth reporting that Safe Place interventions are effective; 84\% of youth completing the evaluation $(n=145)$, indicated that they felt safer upon entering a Safe Place site, and 76\% reported that the program helped them to start resolving the presenting problem and that the program had a positive impact on their lives. $90 \%$ of youth surveyed would use the Safe Place program again if they needed help and $90 \%$ would recommend the use of the program to friends who needed help. In fact, more than one in five of all youth served by Safe Place in 2009 learned about the program from a friend. NSP is optimistic that these outcome measurements will encourage more youth-serving agencies to implement NSP programs. There are currently few concrete outcome measurements utilized by youth organizations and, as an established evidence-based program NSP, can assist many of these agencies as they search for 
effective outcome measurements currently tracked by many funding agencies.

Although the results of early data analysis are promising, measurement of success is largely dependent upon the local agency's consistency and quality of data reporting via the NSP online database. NSP has documented and publicized the value of the online database, yet database use is still not significant; roughly $10 \%$ of partnering agencies fail to consistently report any data, only $15.9 \%$ of partnering agencies are reporting pre/post student worksheet information and only $17.3 \%$ are reporting use of the youth evaluations. Youth evaluations are being completed by only $2 \%$ of the total number of youth being helped through Safe Place.

This lack of reporting occurs for several reasons. Often there is a disconnect between the outreach personnel of the agency and the shelter-which is the point most of the Safe Place documentation occurs. If all of the Safe Place duties fall upon one staff person who may also be overwhelmed with numerous other duties, including direct service, they may not have the time to collect and input the required data. The responsibilities of implementing the program are many and coordinators must often choose between outreach or quality assurance and reporting. Many agencies already working on limited budgets have had to cut staff positions to accommodate decreased funding. Because the need for services has not decreased, but in many cases increased, many agencies are forced to pile multiple roles and job responsibilities upon the remaining personnel. In some cases, the personnel at the local agencies fail to recognize the value of data collection and reporting; personnel who are doing the data collection and input are often disconnected from the reporting, measurement and evaluation of the program and/or agency. NSP is devoting attention to resolving data collection at both the local and national level with the introduction of an online database that can be easily accessed by programs across the nation and the creation of a new NSP staff position to oversee program development and research.

The transient nature of the population makes it difficult not only to provide the youth with interventions but also to successfully measure. The 2003 Incidence and Prevalence of Homeless and Runaway Youth report summarizes the difficulty of any measurement of the homeless, runaway, and throwaway youth (HRTY) population:

[T]here is little empirical evidence about the prevalence or incidence of homelessness or of becoming a runaway or a throwaway, largely because of the challenges inherent in studying this population: contradictory definitions of what constitutes homeless, runaway, and throwaway experiences; an absence of standardized methodology for sampling HRTY; and an over-reliance on data from shelters and agencies.
Despite their large numbers, HRTY are an understudied and undercounted population. Carefully collected data on this population are rare and findings can be inconsistent, largely because sample sizes tend to be small. The result is an incomplete understanding of the characteristics, lifestyles, problems, and needs of homeless youth. (Greene et al. 2003, pp. 1-1)

\section{Future Research}

Youth-serving agencies strive for quality services that can have the most positive impact on the youth they serve. By identifying the best practices of successful program use, NSP can establish better guidelines for program implementation and provide better support for new programs or current struggling programs. Future research should help determine the impact of the Safe Place program on the lives of the youth who use it. The challenge in conducting such research is that Safe Place services end after connecting youth with resources in their area and NSP currently gathers only a little follow up data on youth once they enter shelter services. Outside of this connection and provision of immediate safety, services to the youth who use the program fall within the purview of the local partnering agency. However, an examination of the impact of connection with services would help determine the value of the Safe Place program to the individual youth. Particular areas of research that would be needed include identifying the elements of the Safe Place program that reliably establish meaningful effects on youth, as demonstrated by a reduction in risk behavior, the acquisition of skills, community involvement, and motives for youth participation. Furthermore, because the Safe Place program is ultimately designed to help keep communities safe for youth, future research should examine juvenile justice statistics, police and emergency room records, school records, etc., before and after the start of a program, so that the full impact of a community's decision to implement the Safe Place program may be determined. While this approach is limited in terms of revealing NSP's service benefit to individual youth, understanding NSP's true reduction of the number of youth on the streets, dropping out of school, receiving emergency care and committing survival crimes is a measure of NSPs impact on local communities and effectiveness as a whole. Research partnerships have been formed with faculty at both Indiana University and University of Louisville and a 3 year research plan has been developed with plans to evaluate the effectiveness and impact of the program on the youth utilizing Safe Place and the communities implementing the program. These research partnerships will facilitate the shift to evidence-based evaluation and programming and thus 
support NSP's goal of securing federal funding necessary for program enhancement and expansion.

\section{Conclusion}

Homeless, runaway, and throwaway youth are a large, vulnerable and high-risk population. As an outreach and prevention program, National Safe Place fills a void in the delivery of services and is uniquely designed to provide a comfortable, non-threatening way for youth to access services and immediate safety when experiencing a crisis or seeking refuge from potentially dangerous environments. With the support of the business and civic sectors, the Safe Place system offers services and social support that are critical to both positive youth development and decreasing the number of youth who find it necessary to run away.

In an effort to establish the Safe Place program as an effective outreach and prevention strategy designed to help youth in need, National Safe Place has shifted toward evidence based evaluations and programming with a comprehensive data information system that allows for more effective measurements of its prevention and outreach services. National Safe Place continues to publicize its latest research findings and the nature of its comprehensive approach initiative designed to strengthen the capacity of service delivery to runaway, homeless and at-risk youth, build effective community partnerships and increase and diversify human and financial resources. The interventions of NSP are critical to the health and safety of the thousands of vulnerable youth across the county that turn to the Safe Place network of sites each year for assistance; expanding research approaches, funding opportunities and program growth are significant steps towards the National Safe Place mission of providing help to all young people in crisis.

\section{References}

Baron, S. W. (2003). Street youth violence and victimization. Trauma, Violence and Abuse, 4(1), 22-44.

Benoit-Bryan, J. (2008). National runaway switchboard 2008 reporter's source book on runaway and homeless youth: A guide for media about runaway and homeless youth. Research compiled from Federal documents, published articles, and caller data from the National Runaway Switchboard. Chicago: National Runaway Switchboard. http://www.nrscrisisline.org/ media/documents/2008MediaSourcebook.pdf.

Center for Systems Integration. (2009). Colorado rural demonstration community readiness assessment. Denver, CO: Colorado Department of Human Services.

Condly, S. (2006). Resilience in children: A review of literature with implications for education. Urban Education, 41(3), 211-236.

Dedel, K. (2006). Juvenile runaways guide no. 37. Washington, DC: Center for Problem Oriented Policing.
Greene, J., \& Ringwalt, C. L. (1998). Pregnancy among three national samples of runaway and homeless youth. Journal of Adolescent Health, 23(6), 370-377.

Greene, J., Ennett, S., \& Ringwalt, C. (1999). Prevalence and correlates of survival sex among runaway and homeless youth. American Journal of Public Health, 89(9), 1406-1409.

Greene, J., Sanchez, R., Harris, J., Cignetti, C., Akin, D., \& Wheeless, S. (2003). Incidence and prevalence of homeless and runaway youth: Final report. U.S. Department of Health and Human Services, Office of the Assistant Secretary for Planning and Evaluation, Office of Planning, Research and Evaluation Administration for Children and Families. Research Triangle Park, NC.

Hagan, J., \& McCarthy, B. (1998). Mean streets: Youth crime and homelessness. Cambridge: Cambridge University Press.

Hammer, H., Finkelhor, D., \& Sedlak, A. (2002). Runaway/thrownaway children: National estimates and characteristics. National incidence studies of missing, abducted, runaway, and thrownaway children. Washington, DC: Office of Juvenile Justice and Delinquency Prevention.

HHS. (1994). National study of protective, preventive and reunification services delivered to children and their families. U.S. Department of Health and Human Services, Administration for Children and Families, Children's Bureau. From http://www. acf.hhs.gov/programs/cb/pubs/97natstudy/index.htm (last retrieved February 20, 2010).

James Bell Associates. (2002). Bridging the gap between child welfare and communities. Lessons learned from the family preservation and family support (FP/FS) services implementation study. Issue paper \#2: Administration for children and families. Arlington, VA: U.S. Department of Health and Human Services.

Kipke, M. D., Simon, T. R., Montgomery, S. B., Unger, J. B., \& Iversen, E. F. (1997). Homeless youth and their exposure to and involvement in violence while living on the streets. Journal of Adolescent Health, 20(5), 360-367.

Molnar, B., Shade, S., Kral, A., Booth, R., \& Watters, J. (1998). Suicidal behavior and sexual/physical abuse among street youth. Child Abuse and Neglect, 22(3), 213-222.

National Runaway Switchboard. (2008). Crisis call log and program services report, 2007 (http://www.1800runaway.org/news_events/ call_stats.html).

Nielsen Company. (2009). How teens use media: A nielsen report on the myths and realities of teen media trends. From http://www. blog.nielsen.com/nielsenwire/reports/nielsen_howteensusemedia_ june09.pdf. (last retrieved 17 Feb 2010).

Ringwalt, C. L., Greene, J., \& Robertson, M. J. (1998). Familial backgrounds and risk behaviors of youth with thrownaway experiences. Journal of Adolescence, 21, 241-252.

Rotherman-Borus, M. J., Song, J., Gwadz, M., Lee, M., Van Rossem, R., \& Koopman, C. (2003). Reductions in HIV risk among runaway youth. Prevention Science, 4(3), 173-187.

Sedlak, A. J., Finkelhor, D., Hammer, H., \& Schultz, D. J. (2002). National estimates of missing children: An overview. Washington, DC: U.S. Department of Justice, Office of Justice Programs, Office of Juvenile Justice and Delinquency Prevention.

Thompson, S. J., Bender, K. A., Lewis, C. M., \& Watkins, R. (2008). Runaway and pregnant: Risk factors associated with pregnancy in a national sample of runaway/homeless female adolescents. Journal of Adolescent Health, 43(2), 125-132.

U.S. General Accounting Office. (1989). Homelessness: Homeless and runaway youth receiving services at federally funded shelters. Rockville, MD: National Institute of Justice.

Whitbeck, L., Hoyt, D., \& Yoder, K. (1999). A risk-amplification model of victimization and depressive symptoms among 
runaway and homeless adolescents. American Journal of Community Psychology, 27(2), 273-296.

Whitbeck, L., Hoyt, D., Yoder, K., Cauce, A., \& Paradise, M. (2001). Deviant behavior and victimization among homeless and runaway adolescents. Journal of Interpersonal Violence, 16(11), $1175-1204$.

\section{Author Biographies}

Sara M. Walsh is a doctoral student in the Department of Criminal Justice at Indiana University, Bloomington. Past research has included examining youth victimization and policy responses. Her current research interests include cultural, gender and critical geography studies and the personal safety advice directed at emerging adults.
Robin E. Donaldson is the Program Development and Research Director for National Safe Place. Ms. Donaldson's main research interests include evidence-based programming, risk reductions associated with runaway and homeless youth, and enhancing community protective factors to support youth in need. 